\title{
Nursing diagnosis Noncompliance to treatment in men with hypertension
}

\author{
Diagnóstico de enfermagem Falta de adesão ao tratamento em homens com hipertensão
}

Talliton Uchôa de Araújo ${ }^{1}$, Nuno Damácio de Carvalho Félix ${ }^{1}$, Natana de Morais Ramos ${ }^{1}$, Célida Juliana de Oliveira $^{1}$, Angélica Isabely de Morais Almeida ${ }^{2}$

Objective: to identify the frequency of occurrence of nursing diagnosis Noncompliance of treatment in men with high blood pressure, its defining characteristics, and related factors. Methods: a Cross-sectional study involving 44 men with hypertension by applying a validated instrument for identification of nursing diagnosis. Results: the diagnosis frequency of occurrence was $56.8 \%$, the most present defining characteristics were the inadequate management of nonpharmacological treatment $(p=0.000)$ and adherence failure of indicative behavior $(\mathrm{p}=0.000)$. The most common related factors were deficient knowledge for the monitor of the nondrug treatment regimen $(p=0.000)$ and insufficient teaching ability of health staff $(p=0.002)$. Conclusion: it was found a high frequency of diagnosis in men and the data point to the need for training of health professionals for the development of skills in promoting adherence of men to the treatment of hypertension.

Descriptors: Nursing Diagnosis; Patient Compliance; Hypertension; Men.

Objetivo: identificar a frequência de ocorrência do diagnóstico de enfermagem Falta de adesão ao tratamento em homens com hipertensão arterial, suas características definidoras e fatores relacionados. Métodos: estudo transversal, realizado com 44 homens com hipertensão aplicando-se um instrumento validado para identificação do diagnóstico de enfermagem. Resultados: a frequência de ocorrência do diagnóstico foi de $56,8 \%$, as caraterísticas definidoras mais presentes foram Manejo inadequado do tratamento não medicamentoso $(p=0,000)$ e Comportamento indicativo de falha na adesão $(p=0,000)$. Os fatores relacionados mais frequentes foram Conhecimento deficiente para o seguimento do regime terapêutico não medicamentoso $(p=0,000)$ e Habilidade de ensino insuficiente da equipe de saúde $(p=0,002)$. Conclusão: foi encontrada alta frequência do diagnóstico nos homens e os dados apontam a necessidade de capacitação dos profissionais de saúde quanto ao desenvolvimento de habilidades na promoção da adesão dos homens ao tratamento da hipertensão.

Descritores: Diagnóstico de Enfermagem; Cooperação do Paciente; Hipertensão; Homens.

\footnotetext{
${ }^{1}$ Universidade Regional do Cariri. Crato, CE, Brazil.

${ }^{2}$ Universidade Federal do Ceará. Fortaleza, CE, Brazil. 


\section{Introduction}

Adherence to chronic diseases treatment is included in the research priorities of the National Health System. Despite its complexity, the evaluation of this phenomenon has constantly been carried out through the use of validated instruments, seeking strength in the evaluation process ${ }^{(1)}$.

Hypertension is a chronic multifactorial condition characterized by high and sustained levels of blood pressure, with an average prevalence of $32.0 \%$ for Brazilian adults, reaching more than $50.0 \%$ of individuals aged 60 to 69 years old and $75.0 \%$ in individuals over 70 years old ${ }^{(2)}$.

One of the risk factors for hypertension is the gender ${ }^{(1)}$. Studies have shown a predominance of the female in the involvement of this disease, and also a poor adherence to treatment, although more women take care of their health and their family ${ }^{(3-4)}$. On the other hand, men die more than women by cardiovascular diseases, since the existing masculine models can jeopardize the health of this population ${ }^{(5)}$.

In this context, the nurse must be entered in the identification and tracking of this nursing problem, implementing actions with the purpose of achieving the desired results. This professional integrates multidisciplinary groups to develop joint charitable and educational activities and implements programs and consultations in Primary Health Care, deepening their theoretical and practical knowledge of the body(6).

As one of the tools for this identification, the systematization of nursing care through the nursing process has been instrumental in monitoring people with borderline blood pressure and hypertension, sensitizing them about their health condition and agreeing goals and plans of how to follow their care $^{(1)}$. Among the stages of this process, there is the development of nursing diagnoses, which aims to identify and treat human responses to phenomena or health problems, making a valuable tool guide the care planning ${ }^{(7)}$. Adherence is one of those phenomena which nursing should identify and specify from diagnosis drawn by nurses.

The nursing diagnosis $^{(8)}$ Noncompliance of NANDA International (NANDA-I) was recently reviewed and validated in people with hypertension since this population tends to have high failure rates in treatment adherence ${ }^{(9)}$.

Early identification of this diagnosis by the nurse becomes important so that effective strategies are found and implemented by nursing to provide adequate follow-up to established treatment for hypertension. Thus, it must be considered the context of the population and risk factors for the development of hypertension, in particular, the gender of the patients and their specificities. In this context, the male is inserted who have lower adherence to treatment of hypertension. However, this is not a closed conclusion, because these individuals are always fewer in research ${ }^{(4)}$.

Thus, the lack of research specifically aimed at men hinders the diffusion of the factors that interfere with adherence to treatment by them, configured as a problem, in which nurses need to identify these needs care in men. Thus, the research contributes to this identification from the establishment of the nursing diagnosis, highlighting the characteristics that define it, as well as factors related to the specific characteristics of men, favoring the further development of actions focused on this population.

Therefore, it was aimed to identify the frequency of occurrence of nursing diagnosis Noncompliance to treatment in men with high blood pressure, its defining characteristics, and related factors.

\section{Methods}

Cross-sectional study with three teams of the Family Health headquarters in the city of Acopiara, located in the South Central region of the state of Ceará, Brazil. The teams were chosen because they have the largest number of men with high blood pressure, encouraging to collaborate with the research from 
previous visits to the local recognition, presentation of research and its purpose.

The study included 44 men with hypertension, registered and monitored in the units obtained from the demand for health services by the patients between August and October 2015.

The inclusion criteria were based on previous studies on the diagnosis ${ }^{(9-11)}$, seeking uniformity in the criteria for selection of participants, since these studies are relevant in the process of analyzing the results obtained in the research. These criteria were: age less than 18 years old; Have a medical diagnosis of hypertension for at least one year; Be in drug treatment for hypertension for at least six months; Be guided at the time of data collection. Men with diabetes mellitus together with hypertension were excluded from the research. Such exclusion is justified by the literature noted that the association with diabetes can generate differentiated adherence responses in people with hypertension ${ }^{(12)}$. An increasing number code was used in this study to ensure the anonymity of the participants.

After approval of the participants, a standard form prepared and validated instrument for data collection for the identification of the nursing diagnosis Noncompliance was applied in people with hypertension ${ }^{(9)}$, addressing the socio-demographic characteristics (age, gender, color, occupation, education, family income, marital status), clinical features (weight, height, blood pressure, body mass index), aspects related to adherence to treatment of hypertension, the defining characteristics and factors related to the development of non-compliance, being used for inference of the studied diagnostic.

For the collection of anthropometric data (weight and height), an anthropometric scale was used with $150 \mathrm{~kg}$ capacity (kg) and accuracy of 100 grams (g), which had graduated metal rod in centimeters (cm) to the participants in the health service. To collect these data from men on home visits, a digital scale, and a portable stadiometer was used. The body mass index $(\mathrm{kg} / \mathrm{m} 2)$ was calculated, and the men were classified considering the cutoff point proposed by the Ministry of Health ${ }^{(13)}$. The value of the blood pressure was measured at the end of the application form to ensure that the individual is kept in physical and mental rest conditions.

At the end of data collection, the inference of the nursing diagnosis Noncompliance was made with the aid of two specialist nurses in this diagnosis, identified the defining characteristics and related factors presented by the participating men, without disagreement for the inferences diagnosis.

The experts were selected from the search in the publications on that diagnosis, aiming at attracting professionals inserted in "caririense" region and members of research groups with emphasis on elements in nursing phenomena directed to cardiovascular health. Specialist nurses were notified of the search scope, the proposed methods and the availability required for participation, and the acceptance certificate by signing the Informed Consent Form. After the agreement, the forms collected were sent for determination of whether or not the diagnosis.

The record of the data was performed in Excel 2013 electronic program for Windows, paying attention to the frequency of occurrence (absolute and percentage), the measures of dispersion and central tendency (mean, median, standard deviation). Then, the data were processed using the Statistical Package for the Social Sciences version 20.0. Data were organized in three worksheets: the first with the presence of nursing diagnosis, clinical, epidemiological and socio-demographic characteristics; the second with the defining characteristics and the third with the related factors. Chi-square and Fisher tests were applied obtaining the odds ratio and $95.0 \%$ confidence interval, considering the statistical significance with $\mathrm{p}<0.05$.

The study complied with the formal requirements contained in the national and international standards of regulatory research involving human beings. 


\section{Results}

From the diagnostic inference of specialist nurses on the instrument data, it was found in the participating men the frequency of occurrence of $56.8 \% \quad(n=25)$ of the nursing diagnosis Noncompliance to treatment of hypertension. Table 1 shows the comparison of variables associated with socioeconomic and clinical characteristics of the participants with and without the nursing diagnosis on the non-compliance.

As for the men with the diagnosis, there was a prevalence of elderly men $(80.0 \%)$, but with range 45-93 years old $(S D=13.3)$, white $(60.0 \%)$ with companion $(72.0 \%)$ and average income of a Brazilian minimum wage in 2015 ( $\mathrm{R} \$ 788.00$ ), from the retirement (76.0\%). The low education prevailed, with men having between one and two years of education (52.0\%), followed by illiteracy (28.0\%).
Considering the group of men who did not have the diagnosis, it was also found the prevalence of elderly (89.5\%), with the same average age (71.8), but with the higher standard deviation (15.3) and greater range of age (18-96 years old). Most declared being white $(68.4 \%)$ with a partner $(52.6 \%)$ and illiterate $(42.1 \%)$. However, there was a greater quantity of men with more study time (12 years of education completed - 10.5\%). The average income of a Brazilian minimum wage from the retirement $(84.2 \%)$ also prevailed in this group. The correlation of sociodemographic and clinical variables with the presence of nursing diagnosis Noncompliance was not statistically significant.

Table 2 shows the distribution of the defining features providing the critical and clinical judgment about the presence of the diagnostic study in men undergoing treatment for hypertension.

Table 1 - Distribution of socioeconomic and clinical characteristics of men with $(n=25)$ and without $(n=19)$ the nursing diagnosis Noncompliance to treatment of hypertension

\begin{tabular}{|c|c|c|c|c|c|c|c|c|c|}
\hline \multirow[b]{2}{*}{ Variables } & \multicolumn{3}{|c|}{ With diagnosis } & \multicolumn{3}{|c|}{ Without diagnosis } & \multirow[b]{2}{*}{ Odds-ratio } & \multirow{2}{*}{$\begin{array}{c}\text { Confidence } \\
\text { interval }\end{array}$} & \multirow[b]{2}{*}{$\mathbf{p}$} \\
\hline & Mean & Median & $\begin{array}{l}\text { Standard } \\
\text { deviation }\end{array}$ & Mean & Median & $\begin{array}{l}\text { Standard } \\
\text { deviation }\end{array}$ & & & \\
\hline Age & 71.8 & 75.0 & 13.3 & 71.8 & 75.0 & 15.8 & 0.64 & $0.18-2.2$ & 0.490 \\
\hline Years of study & 1.8 & 1.5 & 1.9 & 2.3 & 1.0 & 3.7 & 0.53 & $0.15-1.88$ & 0.328 \\
\hline Body mass index & 27.8 & $27, .6$ & 4.5 & 26.0 & 25.7 & 3.5 & 1.18 & $0.32-4.36$ & 0.797 \\
\hline Sistolic Blood presure (mmHg) & 138.0 & 140 & 19.8 & 128.9 & 120 & 14.9 & 2.34 & $0.67-8.15$ & 0.176 \\
\hline Diastolic blood pressure (mmHg) & $83 ., 2$ & 80 & 11.4 & 81.6 & 80 & 8.98 & 1.70 & $0.48-5.93$ & 0.402 \\
\hline
\end{tabular}

Table 2 - Defining characteristics identified in men with the nursing diagnosis Noncompliance $(n=25)$

\begin{tabular}{|c|c|c|c|c|}
\hline Defining characteristics & n (\%) & Odds ratio & Confidence interval & $\mathbf{p}$ \\
\hline Inappropriate management of nonpharmacological treatment & $19(76.0)$ & 26.91 & $4.77-151.66$ & 0.000 \\
\hline Indicative behavior of adherence failures & $19(76.0)$ & 26.91 & $4.77-151.66$ & 0.000 \\
\hline Difficulty in meeting decisions agreed with the health team & $12(48.0)$ & 16.61 & $1.91-144.23$ & 0.002 \\
\hline Inapropriate management of pharmacological treatment & $10(40.0)$ & 1.86 & $0.51-6.83$ & 0.522 \\
\hline Evidence of hypertension exacerbation & $4(16.0)$ & - & - & 0.122 \\
\hline
\end{tabular}


The form used contains six defining characteristics based on the NANDA-I. However, only five of them were identified in participants with the diagnosis. The most prevalent were the inappropriate management of nonpharmacological treatment (76.0\%) and indicative behavior adherence failure (76.0\%), and it was observed a high level of statistical significance $(\mathrm{p}=0.000)$ between the presence of nursing diagnosis on the non-compliance and the prevailing defining characteristics. Regarding the value of the odds ratio, it was seen that both diagnoses presented, respectively, 26.9 and 16.6 of more chance to get the diagnosis Noncompliance when present.

As regards the simultaneous presence of defining characteristics for participants in the diagnosis, $44.0 \%$ of men showed at least two characteristics, followed by three simultaneous characteristics of the sample on $24.0 \%$, and four characteristics in $20.0 \%$ of men. There were $12.0 \%$ of the evaluated men only with a characteristic.

The factors related to the nursing diagnosis on the lack of membership were identified in men with hypertension participating in this study, with seven of the 12 factors contained in the instrument (Table 3).

Table 3 - Identified related factors in men with the nursing diagnosis on the non-compliance $(n=25)$

\begin{tabular}{|c|c|c|c|c|}
\hline Related factors & n (\%) & $\begin{array}{l}\text { Odds } \\
\text { ratio }\end{array}$ & $\begin{array}{c}\text { Confidence } \\
\text { interval }\end{array}$ & $\mathbf{p}$ \\
\hline $\begin{array}{l}\text { Insufficient knowledge to monitor the } \\
\text { non-drug treatment regimen }\end{array}$ & $23(92.0)$ & 24.91 & $4.37-141.79$ & 0.000 \\
\hline $\begin{array}{l}\text { Insufficient teaching ability of the health } \\
\text { staff }\end{array}$ & 21 (84.0) & 9.00 & 2.17-37.17 & 0.002 \\
\hline $\begin{array}{l}\text { Beliefs and values of the individual re- } \\
\text { lated to health/disease }\end{array}$ & $13(52.0)$ & 9.20 & $1.74-48.52$ & 0.005 \\
\hline Failure coverage of the health system & $9(36.0)$ & 4.78 & $0.89-25.58$ & 0.081 \\
\hline Impairment in personal capacity & $9(36.0)$ & 4.78 & $0.89-25.58$ & 0.081 \\
\hline Lack of support from significant people & $9(36.0)$ & 1.57 & $0.42-5.82$ & 0.534 \\
\hline Cultural influences & $2(8.0)$ & - & - & 0.498 \\
\hline
\end{tabular}

Among the related factors found in participants with the nursing diagnosis, there was a prevalence of the factors related to deficient knowledge of the following non-drug treatment regimen (92.0\%), insufficient teaching ability of health staff (84.0\%) and beliefs and values of the individual related to health/disease (52.0\%). Both related factors showed a high level of statistical significance $(\mathrm{p}<0.05)$. Through the odds ratio, the related factors presented, respectively, the high odds ratio of $24.9,9$ and 9.2. It is important to note that evidenced related factors have a strong connection with the most prevalent defining characteristics in men with a non-compliance to treatment of hypertension, leading to the development of diagnosis in the male.

\section{Discussion}

Among the main limitations of this study, there is the failure to adopt the results as a cause and effect due to the transverse aspect of the study, the extensive form, the sparse literature for a specific discussion of data and the difficulty in capturing the men in the Primary Service. However, participants were available for filling the instrument. It is suggested the development of longitudinal studies with larger and using other methods for performing and analyzing data samples.

It is important to note that the use of the validated instrument for the identification of the nursing diagnosis on the non-compliance allows nurses to recognize the defining characteristics and related factors of the consistent way with the clinical presentation of the patient, leading to the establishment of planned and implemented interventions in the best way.

A similar study of 38 people of both genders identified more often diagnosed in females (78.5\%) (11). Probably, men showed lower frequency, unlike this study, due to lower demand for these health services, and data collection sites of such research. Therefore, these data are related to the fact that men are not captured in the collection process in studies involving the diagnosis, thus demonstrating how this population is still in the tangent of research and need 
to be studied further on the theme.

The relationship between the clinical and socioeconomic characteristics did not present statistical significance. However, research refer mainly positive influence of living with a partner for men's health, due to greater access to information, the adoption of healthy behaviors and the use of health services $^{(10)}$, also being referred to the damage on compliance related to the low level of education ${ }^{(14)}$ and the ratio of the blood pressure uncontrolled with flaws in drug and non-drug therapy implemented ${ }^{(10)}$.

Participants with the nursing diagnosis identified the five defining characteristics are presenting results similar to other studies ${ }^{(9,11)}$. In this study, the frequency, the statistical significance, and the odds ratio of two defining characteristics were identical, being the inappropriate management of nonpharmacological treatment and indicative behavior of compliance failures. The literature refers to them as being the most sensitive to the identification of the nursing diagnosis Noncompliance ${ }^{(9)}$.

The defining characteristic difficulty in meeting decisions agreed with the health team was another that showed statistically elevated odds ratio significance when associated with the presence of diagnostic study.

These findings may be related to the difficulty in this group to recognize their health needs, cultivating the thought that rejects the possibility of becoming ill, keeping today the cultural issue of male invulnerability of their social role provider and hero. Also, there is the conformation of access to primary care services, historically structured to meet women and children, whose working hours coincide with the working hours of men. This complicates the care of males, culturally family providers and the reference as workers $^{(15)}$.

As for the association of the related factors and the presence of the diagnosis in male participants, it was found a high statistical significance in three of these factors. Poor knowledge to monitor the nondrug regimen had the highest significance, as well as a higher odds ratio. This related factor was also the most identified in other studies with participants of both genders ${ }^{(9,11)}$.

Such a related factor is directly related to the development of compliance failures, and may be a consequence of failures in the teaching and health education developed by health professionals. It is highlighted the importance of actions that promote patient awareness of the harmful effects of uncontrolled high blood pressure and risks, benefits and peculiarities inherent to the treatment, and the nurse's individual incentive for him to become the proper care active ${ }^{(6)}$.

Insufficient teaching ability of the health team also showed statistically significant and high odds ratio, despite being pointed out by the literature as a secondary factor related ${ }^{(9)}$, showing that some of these factors can be evidenced in specific populations and are related to the development of nursing diagnosis Noncompliance. Similarly, there is an evidence of a deficiency in health education activities provided by the professionals of health facilities since the establishment of the defining characteristics listed above.

The success of adherence to treatment of hypertension depends on a sum of actions and the joint participation of patients, healthcare staff, and family. Early identification of the elements that affect adherence negatively, through the investigation of the defining characteristics and factors related to the nursing diagnosis Noncompliance presence can provide nurses ways to establish effective interventions to resolve the diagnosis ${ }^{(6,9,11)}$.

As for the beliefs factor and the individual values related to the health/disease had a high chance, pointing, once again, the prospect that men seek fewer health services as a result of male hegemonic culture, requiring more targeted studies to this population, so that address their specific care needs $s^{(16)}$. Women with hypertension are at a more controlled pattern than men with the same disease, and essential to seek, in other variables, new factors that may interfere with 
treatment adherence ${ }^{(17)}$.

Actions to promote and improve adherence to treatment of hypertension are constant in the academic, healthcare and managerial in the health context, requiring the identification of variables that might compromise this phenomenon.

\section{Conclusion}

The study allowed the identification of the high number of men with nursing diagnosis Noncompliance to treatment of hypertension, with two defining characteristics more present and statistically significant, which were related to the management of non-drug treatment and indicative behaviors of compliance failures. The most common factors related to education are the disability health staff, inadequate knowledge to follow the treatment regimen and beliefs and the individual values related to health/disease process.

The identification instrument of nursing diagnosis Noncompliance was significant in the application in men with hypertension and the data included from that point to the imminent need for further studies to identify nursing problems related to failed adherence to treatment of hypertension directed to this population. It is necessary that health professionals and public managers seek to understand the factors involved to resolve them and ensure consistent care in health with the needs of society, especially the males.

\section{Collaborations}

Araújo TU and Félix NDC contributed to the conception and design. Ramos NM and Almeida AIM contributed to the writing and critical review of the relevant article. Oliveira $\mathrm{CJ}$ contributed to the final approval of the version to be published.

\section{References}

1. Ministério da Saúde (BR). Secretária de Atenção à Saúde. Departamento de Atenção Básica. Estratégias para o cuidado a pessoa com doença crônica: hipertensão arterial sistêmica. Caderno de Atenção Básica no 37. Brasília: Ministério da Saúde; 2013.

2. Sociedade Brasileira de Cardiologia. Sociedade Brasileira de Hipertensão. Sociedade Brasileira de Nefrologia. VI Diretrizes Brasileiras de Hipertensão. Arq Bras Cardiol. 2010; 95(Suppl 1):1-51.

3. Raymundo ACN, Pierin AMG. Adherence to anti-hypertensive treatment within a chronic disease management program: a longitudinal, retrospective study. Rev Esc Enferm USP. 2014; 48(5):811-9.

4. Nogueira D, Faerstein E, Coeli CM, Chor D, Lopes CS, Werneck GL. Reconhecimento, tratamento e controle da hipertensão arterial: Estudo Pró-Saúde, Brasil. Rev Panam Salud Publica. 2010;27(2):3-9.

5. Schwarz E, Gomes R, Couto MT, Moura EC, Carvalho AS, Silva SFC. Política de saúde do homem. Rev Saúde Pública. 2012; 46(Supl):108-16.

6. Santos JC, Florêncio RS, Oliveira CJ, Moreira TMM. Adesão do idoso ao tratamento para hipertensão arterial e intervenções de enfermagem. Rev Rene. 2012; 13(2):343-53.

7. Conselho Federal de Enfermagem. Resolução no 358/2009. Dispõe sobre a Sistematização da Assistência de Enfermagem e a implementação do processo de enfermagem em ambientes, públicos ou privados, em que ocorre o cuidado profissional de Enfermagem. Brasília: Conselho Federal de Enfermagem; 2009.

8. NANDA Internacional. Diagnósticos de enfermagem da NANDA: definições e classificação 2015-2017. Porto Alegre: Artmed; 2015.

9. Oliveira CJ, Araújo TM, Costa FBC, Costa AGS. Clinical validation of the nursing diagnosis "noncompliance" among people with hypertension. Esc Anna Nery. 2013; 17(4):611-9. 
10. Nascimento ACG, Alves ACP, Almeida AIM, Oliveira CJ. Características da adesão terapêutica em pessoas com hipertensão arterial e identificação do diagnóstico de enfermagem "falta de adesão" na atenção primaria. Rev APS. 2013; 16(4):36577.

11. Bertoletti AR, Costa AGS, Costa FBC, Oliveira ARS, Oliveira CJ, Araújo TL. Diagnóstico de enfermagem falta de adesão em pacientes acompanhados pelo programa de hipertensão arterial. Rev Rene. 2012; 13(3):623-31.

12. Alves BA, Calixto AATF. Aspects determinants of adherence to treatment of hypertension and diabetes in a primary care unit in the state of São Paulo. J Health Sci Inst. 2012; 30(3):255-60.

13. Ministério da Saúde (BR). Secretária de Atenção à Saúde. Departamento de Atenção Básica. Estratégias para o cuidado a pessoa com doença crônica: obesidade. Brasília: Ministério da Saúde; 2014.
14. Vitor AF, Monteiro FPM, Morais HCC, Vasconcelos JDP, Lopes MVO, Araújo TL. Survey of the followtherapeutic patients with hypertension. Esc Anna Nery. 2011; 15(2):251-60.

15. Silva PAS, Furtado MS, Guilhon AB, Souza NVDO, David HMSL. Saúde do homem na visão dos enfermeiros de uma unidade básica de saúde. Esc Anna Nery. 2012; 16(3):561-8.

16. Separavich MA, Canesqui AM. Saúde do homem e masculinidades na Política Nacional de Atenção Integral à Saúde do Homem: uma revisão bibliográfica. Saúde Soc. 2013; 22(2):415-28.

17. Pierin AMG, Marroni SN, Taveira LAF, Benseñor IJM. Hypertension control and related factors at primary care located in the west side of the city of São Paulo, Brazil. Ciênc Saúde Coletiva. 2011; 16(sup.1):1389-400. 